\title{
Disorder, social capital, and norm violation: Three field experiments on the broken windows thesis
}

Rationality and Society 2015, Vol. 27(I) 96-126

(C) The Author(s) 2015

Reprints and permissions: sagepub.co.uk/journalsPermissions.nav DOI: | 0.1 |77/|043463 | |456|749

rss.sagepub.com

@SAGE

\section{Marc Keuschnigg}

Department of Sociology, LMU Munich, Germany

\section{Tobias Wolbring}

Professorship for Social Psychology and Research on Higher Education, ETH Zurich, Switzerland

\begin{abstract}
Adding to the debate about the "broken windows" thesis we discuss an explanation of minor norm violation based on the assumption that individuals infer expected sanctioning probabilities from contextual cues. We modify the classical framework of rational crime by signals of disorder, local social control, and their interaction. Testing our implications we present results from three field experiments showing that violations of norms, which prevent physical as well as social disorder, foster further violations of the same and of different norms. Varying the net gains from deviance it shows that disorder effects are limited to low-cost situations. Moreover, we provide suggestive evidence that disorder effects are significantly stronger in neighborhoods with high social capital.
\end{abstract}

\section{Keywords}

Broken windows theory, disorder, field experiment, low-cost situations, norm violation, social capital

\section{Corresponding author:}

Marc Keuschnigg, Department of Sociology, Ludwig-Maximilians-University Munich,

Konradstraße 6, 8080I Munich, Germany.

Email: marc.keuschnigg@soziologie.uni-muenchen.de 


\section{Introduction}

Self-interest is a key driver of human behavior. However, in almost all situations behavior is constrained by social rules (i.e. laws, norms) which define the range of acceptable behavior within society. We argue that the extent to which behavior is governed by such rules depends on the level of social control, i.e. the likelihood and the severity of getting sanctioned (for experimental evidence, see e.g. Franzen and Pointner, 2012). Hence, a rational decision on whether to break rules rests on the probability of sanctions and their severity. Thus, the compliance to social rules should depend on the level of social control exerted in a given situation.

We present an explanation of norm-violating behavior, where the probability and severity of social sanctions is inferred from contextual cues. Unlike Becker's (1968) model of crime our approach particularly applies to situations of minor norm violations. Usually, the cost of getting socially sanctioned is relatively low and, therefore, investing in costly search to gain objective information on rates of detection and punishment is not worthwhile. In situations where punishment is expected to be moderate, e.g. breaking socially as opposed to strongly legally sanctioned rules, easily observable indicators of social control should suffice to infer the costs of deviant behavior.

Our theoretical framework integrates two mechanisms which promote the violation of norms: on the one hand, certain forms of previous norm violations (e.g. littering) trigger the violation of the same norm, since doing likewise adds only marginally to the social cost of non-compliance (samenorm inhibition effect). Thus, a growing number of prior norm violations implies a decrease in the expected severity of punishment for individual offenders. On the other hand, observed signs of previous norm violations signal a generally low rate of getting sanctioned and, thus, can spill over to violations of different norms (cross-norm inhibition effect).

The notion that the level of social control is inferred from contextual cues relates to the well-known "broken windows" thesis (BWT). Originally proposed by Wilson and Kelling (1982), the BWT states that physical and social disarray fosters additional norm violations and, therefore, the spreading of disorder (Kelling and Coles, 1996; Skogan, 1990). Put into practice, BWT advocates the removal of signs of disorderliness and incivility in order to curb crime. Empirical findings, however, were rather ambiguous (e.g. Corman and Mocan, 2005; Harcourt and Ludwig, 2006; Kelling and Sousa, 2001) and did not allow decisive conclusions about causality. Since most studies are based on observational data, their results have been questioned on methodological grounds (e.g. Braga and Bond, 2008; Levitt, 2004). Although potential confounders are usually statistically controlled for, with observational data it is nearly impossible to rule out the possibility of biased and inconsistent estimates (e.g. Rosenbaum, 
2010; Rubin, 2008). From a causal inference perspective one would prefer an experimental design to test for the effects of order maintenance.

Focusing on the consequences of disorder for minor norm violations, Keizer et al. (2008) revived the discussion on the BWT with a highly influential empirical contribution. In a series of field experiments they showed that physical disorder (e.g. litter, graffiti) encourages further norm violations by others (littering, non-conformity to trespassing, and stealing). Furthermore, disorder effects seem particularly strong if norms of physical and social order are made apparent by prohibition signs (Keizer et al., 2011).

This paper adds to the discussion on theoretical and empirical grounds. First, we offer a rational choice explanation for norm violations in the context of environmental cues for the level of social control. Second, using social capital as an indicator of social control we propose hypotheses on the effect of local social capital on the level of norm violations as well as on the interaction between local social capital and the strength of disorder signals. Third, our implementation of three field experiments follows the interventionist approach of Keizer et al. (2008). We replicate two of their field experiments on littering and on stealing yielding surprisingly similar results. Moreover, with an adaptation to jaywalking we provide new evidence for the causal effect of "social disorder". Fourth, varying the costs and benefits of deviance we investigate the scope conditions for disorder effects. Fifth, consistent with our theoretical framework we present suggestive evidence on the consequences of local social capital of a neighborhood, which significantly moderates disorder effects.

\section{Theoretical framework}

We develop our theoretical argument in four steps. First, we outline the intuition and scope of a Beckerian rational choice model of norm-violating behavior. Next, framing "broken windows" as signals of low social control we explicate the close relationship between the BWT and theories of rational action, and integrate disorder effects into a framework of deviance in low-cost situations. In a third step, we introduce the concept of social capital and highlight how it fits into the economic approach to human behavior. Finally, we extend the theoretical framework proposing that the strength of disorder effects on further norm violations might vary with the degree of social capital in an area.

\section{Deviance as a rational action}

The most influential rational choice approach to deviant behavior is Becker's (1968) model of crime. It is based on the assumption that actors decide on committing a crime on the basis of a calculation of cost and 
benefit. A social rule is broken if the expected utility of an offense outweighs the net benefits of each of the available alternatives. As long as the expected benefit of deviant behavior is dominated by the potential loss of welfare by getting punished, a rational actor would choose to obey a given social rule. According to the model it is rational for individuals to break a rule as long as the chance of punishment is small compared with the potential gains of deviance.

The model has been extended in several ways (e.g. Braun and Gautschi, 2011; Brown and Reynolds, 1973; Heineke, 1975) and is widely accepted within the rational choice community. Although it adds to our understanding of serious crime, ranging from robbery to tax evasion, we argue that its standard formulation is of limited applicability in the case of minor norm violations. The benefits and costs of littering or jaywalking are so small that they cannot be seriously interpreted as criminal incentives or inhibitors.

Instead, in low-cost situations environmental cues signaling social control gain in relevance. Following Kliemt (1986: 333), in low-cost situations "the individual decision maker has no direct interest in the outcome because she or he will hardly be influenced by the outcome". Hence, when individual costs and benefits are low it is rational to shorten the lengthy and cumbersome decision-making process by the use of heuristics. Likewise, Kirchgässner (1992: 305) argues that "[f]or such decisions, soft incentives like those provided by moral rules can have a much stronger impact than (economic) hard incentives". Consequently, we propose a modification of the Beckerian model to account for low-cost situations, where offenders are interested in avoiding social sanctions and thereby rely on environmental cues.

Usually, actors do not know the probability of punishment and have to form subjective expectations on the basis of incomplete information. One source of information could be official statistics about convictions in the past. However, it appears to be unrealistic to assume that actors invest in costly search when breaking minor norms. Rather they are expected to resort to easily observable context-specific cues to estimate detection and sanction rates for specific locations and social contexts. Framed in a rational choice terminology, the subjective belief on the probability of conviction is a function of signals available in the situation at hand.

In contrast, if gains from deviance are high and if punishment is expected to be severe, signs of low social control should affect behavior to a far lesser extent. In such high-cost situations rational beliefs on the costs of deviant behavior are not formed on easily observable cues alone. Instead, as costs and benefits of deviance increase, people ponder the actual net benefits from deviance and contextual cues become less important for individual decision making (incentivization effect). In consequence, our modification 
of the classical framework applies to violations of moderately sanctioned rules (as opposed to legally sanctioned heavy crime).

\section{Broken windows as signals for social control}

To clarify our theoretical argumentation it is necessary to distinguish two kinds of norms: violated norm and target norm. Defining social norms as behavioral expectations in a community of what ought to be done and omitted, which are enforced by positive and negative reinforcement (e.g. Coleman, 1990; Opp, 1983, 2002), the concept of a violated norm refers to social rules broken by others in the past. In many situations contextual cues, such as physical or social disorder, inform about previous norm violations by others. Subjects can infer from behavioral traces what others have done and what appeared morally acceptable or even normal to them. Thus, others' past behavior can have effects on a subject's belief formation and, therefore, her current behavior. Similarly, other authors argue that previous actions affect descriptive norms (e.g. Cialdini, 2007; Cialdini et al., 1990) and empirical expectations about what other people would do in a similar situation (Bicchieri, 2006; Bicchieri and Xiao, 2009).

The target norm, on the other hand, refers to behavioral expectations about what is morally acceptable in a given situation. The concept is closely linked to Cialdini's (2007) injunctive norms and Bicchieri's (2006) normative expectations. Thereby, a target norm not only specifies "what ought to be done", but also entails the "promise of social sanctions" (Cialdini et al., 1990: 1015) if it is broken. The actors of interest in our three studies, which are targeted by such a norm, are the subjects participating in the field experiment. For example, in one of our field experiments subjects find a lost letter containing money next to a littered mail box. Obviously, in this case the trigger is littering, whereas the target norm is "Don't steal lost letters" or even "Put lost letters in the mail box". Thus, violated and target norm can, but need not necessarily, be identical. Having clarified this, we propose two mechanisms which bring about the effect of disorder on additional norm violations.

Mechanism 1 is rather general and applies to both situations of identical and non-identical norms. It rests on the assumption that signs of non-compliance by others signal the likelihood of norm enforcement by the social environment. Contextual cues such as physical or social disorder allow an inference on the level of social control. Obviously, if there is disorder in a given situation or neighborhood, nobody has prevented norm violations or previously sanctioned them. As a consequence, people lower their expectations about the probability of being punished for deviant behavior and generally have less incentive to comply with the rules. Moreover, disorder as a 
signal for low social control can promote spillover effects where violations of one norm foster non-compliance to non-identical target norms.

Mechanism 2 only comes into effect if violated norm and target norm are identical. Since fixed costs for mending broken windows are high, certain forms of behavior can lead to diminishing marginal costs for future actions. For example, if a location is already littered with garbage, people might regard the effect of throwing an additional piece of litter on the ground as negligible ("Somebody has to clean up the mess anyway, no matter what I do"). As the perception of the severity of a norm violation is at least partly related to its frequency, one can argue that the number of previous norm violations committed by others negatively influences the perceived costs of sanctions. Individuals might regard it as very improbable to be severely punished for an action many people have done before. In a similar vein, Popitz (1968) argues that lacking knowledge on the extent of norm violations in a population can prevent the spread of norm violations. Recent results by Diekmann et al. (2011) are in line with this consideration: providing experimental subjects with information on the misbehavior of their coparticipants significantly increases the individual probability of malpractice. In general, this implies that a growing number of prior norm violations is associated with a decrease in the expected severity of punishment for individual offenders.

As the individual perception of a sanction's gravity decreases, past violations of a norm can encourage similar actions by others. Therefore, the mechanism of diminishing marginal costs gives an additional rationale for cumulative processes of norm violation, such as littering, graffiti, or neighborhood decline. Consequently, signs of deviant behavior by others are expected to induce further violations of the same norm (same-norm inhibition effect) or to spill over to a different target norm (cross-norm inhibition effect).

Both mechanisms give a theoretical underpinning for the causal effect of physical and social disorder on further norm violations stated by the BWT. Advocates of the BWT advise policy makers to influence the decision environment in order to signal social control and, thereby, to deter criminal acts. Probably the most prominent attempt in this regard has been zero-tolerance policing. As suggested by Wilson and Kelling (1982) (see also Kelling and Coles, 1996) the police should sanction minor violations of the law rather severely and physical disorder should be removed instantly. Since physical or social disorder might signal that no one cares, the main aim of these actions is to raise the expected probability that sanctions will be imposed. Thus, fixing broken windows might influence expectations about the probability of punishment for deviant behavior.

Based on these behavioral assumptions and in order to test the broken windows effect, signals of precedent norm violations by others (e.g. littering, 
crossing on a red light) are central stimuli in our experimental design. Looking at the cross-norm inhibition effect appears particularly promising, as it allows us to empirically separate triggers and consequences more clearly. By this and by manipulating the experimental stimulus, one can avoid the basic problem in observational studies that disorder and crime may merely be different dimensions of the same variable (see Sampson and Raudenbush, 1999).

\section{Local social capital and the strength of disorder effects}

As beliefs on other people's capacity and willingness to sanction norm violators form the crucial ingredient of our theoretical considerations, we substantiate our argumentation with respect to social capital. Since the concept of social capital is used rather vaguely and inconsistently in the literature, we first outline basic notions of the term and, second, explicate its relationship to the expected level of social control and the enforcement of social norms.

Broadly speaking, there are two traditions in the interpretation of social capital (for reviews see Franzen and Pointner, 2007; van Deth, 2003). While some scholars define social capital as network-based resources (e.g. Bourdieu, 1984; Burt, 1992; Granovetter, 1973), others see the degree of generalized trust as well as shared norms and values on the level of a community or society at the core of this concept (e.g. Fukuyama, 1995; Putnam, 2000). Integrating both perspectives (e.g. Coleman, 1988, 1990), one can argue that frequent interactions within a group of people stimulate norms of reciprocity and foster mechanisms of reputation. Hence, strong integration should motivate individuals to bear costs of sanctioning, both to defend a group's common values as well as to indicate membership to a specific group.

Moreover, social capital allows for a spatial interpretation. The concept of local social capital reflects a neighborhood's capability for informal social control (e.g. Coleman, 1990; Ostrom, 1999; Ostrom and Ahn, 2003). Others (Brown et al., 2004; Sampson and Raudenbush, 1999; Sampson et al., 1997, 2002) speak in a similar meaning of a neighborhood's collective efficacy, if shared expectations for social control exist and there is a perceived willingness of residents to intervene in cases of norm violations. Again, social interactions are the micro-mechanisms fostering or impeding the emergence of generalized trust and shared norms (Coleman, 1990), which proved to be strongly associated with the degree of informal social control and the extent of norm violations in a neighborhood (Coleman, 1988; Markowitz et al., 2001; Silver and Miller, 2004; Steenbeek and Hipp, 2011).

Consequently, a neighborhood highly endowed with social capital should exhibit stronger social control. Therefore, rational actors should take into 
account the extent of social capital in a specific area when estimating the probability of sanction and deciding whether to violate a norm or not.

In addition to this generally negative local social capital effect on the rate of norm violation, we propose that the signaling effect of disorder varies with the degree of local social capital. If local social capital is low, it is more likely that people feel less attached to their neighborhood, care less about actions of others in the area, or just moved there and do not know anyone. Signals of low social control are not very informative in these areas, since it is common knowledge that crime rates and disorder are usually high in neighborhoods which are low in social capital. The signal is consistent with individuals' expectations about the behavior of neighbors and therefore should not trigger additional norm violations. Hence, the signal of disorder is weaker in low social capital contexts.

In contrast to that, if an area is highly endowed with social capital, people care more about actions of others, and they are more apt to conform to their behavior. Moreover, disorder is an especially strong signal in high social capital areas, because the signal conflicts with expectations derived from local social capital. Thus, we propose an interaction effect of disorder and social capital: the effects of physical and social disorder on norm violations are expected to be stronger in neighborhoods with higher social capital. The proposed interaction implies that the consequences of local social capital are partially substituted by the information derived from disorder signals.

\section{Experimental design}

In order to test the implications of our framework we conducted three field experiments in Munich, Germany. Each study represents a separate experiment, where subjects, acting in their natural environment, did not know they were taking part in a concealed inquiry. In all field experiments we used a (physical or social) disorder treatment to test for an increase in subjects' norm violations. Studies 1 and 2 investigate the same-norm inhibition effect, while study 3 examines the spillover of norm violations from one rule to another. As the scope of our theoretical approach aims at minor norm violations, our experiments focus on minor offenses, i.e. littering, jaywalking, abstaining from helping. Only in study 3 we introduce higher stakes for deviance, testing the scope of our explanation of norm violation. Extending previous results (Keizer et al., 2008) this stealing experiment provides first evidence on the applicability of the BWT to high-cost situations. ${ }^{1}$ Although our field experiments neglect the randomization of participants into specific experimental conditions, the systematic variation of treatments and the nonreactive set-up in a common real-world situation provide for high internal 
and external validity. In their basic set-up studies 1 and 3 are replications of field experiments conducted by Keizer et al. (2008) in Groningen, The Netherlands. Study 2 represents a new design to test for the causal effect of social disorder. In addition, to test for an interaction effect between disorder and the expected level of social control, we chose experimental locations with varying degree of local social capital. To identify locations differing in social capital, we analyzed local social capital measurements from survey data (study 1) as well as from official census data (studies 2 and 3).

\section{Study I: Littering}

Background. The first study examines the consequences of physical disorder and tests for a same-norm inhibition effect in the context of littering. The field experiment was staged at bicycle parking areas of two university dormitories in Munich (the selection of dorms is explicated below). We used garbage as our experimental treatment to reflect physical disorder. The outcome variable of interest is the number of incidents of additional littering by our participants. Our explanation of norm violation implies that observing a littered environment (i.e. physical disorder) increases the inclination of subjects to litter too, as the expected probability of getting sanctioned and/or the expected severity of a sanction decreases. As both mechanisms explaining the broken windows effect coincide in situations of diminishing marginal costs (i.e. violated norm and target norm are identical) the experiment does not allow for separating mechanisms 1 and 2 .

Experimental set-up. To place our participants at both dormitories into a discrete choice situation for or against littering we followed the procedure proposed by Keizer et al. (2008). In July 2010 we attached a non-sense flyer with a rubber band to the handlebar of each bicycle in the parking areas of the dormitories. The flyer depicted a nonexistent car rental firm and read "We are new in town and wish everybody a wonderful Summer 2010", and thus was not prone to be kept by the participants but offered an instant object of littering. The flyers were attached to the handlebars in the early morning between 04:00 and 05:00. In order to use their bicycles, the dormitory inhabitants had to remove them from the handlebars of their bicycles (Figure 1(a)). Thereby, participants faced an incentive to litter as properly disposing of the flyer is obviously more tedious than just throwing it on the ground.

All discarded flyers were collected and counted on the same day in the afternoon (14:00). As littering represents a violation of the dorms' official rules and generally dorms in Munich are kept surprisingly clean, each discarded flyer can be interpreted as a violation of the target norm. Since there were no trash cans 


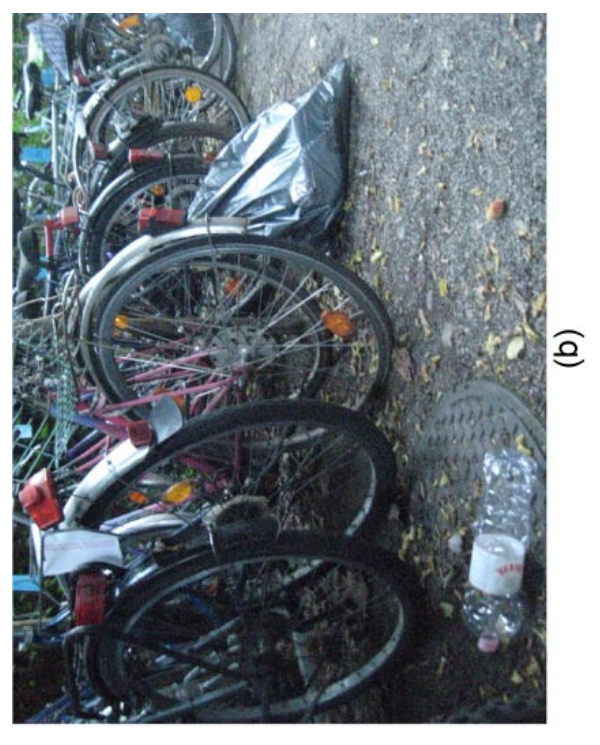

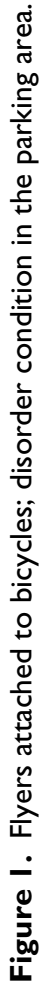


Table I. Number of cases across dormitories and experimental conditions.

\begin{tabular}{llllllr}
\hline $\begin{array}{l}\text { Social } \\
\text { capital }\end{array}$ & Condition & $\begin{array}{l}\text { Number } \\
\text { of flyers } \\
\text { prepared in } \\
\text { the morning }\end{array}$ & $\begin{array}{l}\text { Number of } \\
\text { flyers still } \\
\text { attached in } \\
\text { the afternoon }\end{array}$ & $\begin{array}{l}\text { Effective } \\
\text { number } \\
\text { of cases }\end{array}$ & $\begin{array}{l}\text { Number } \\
\text { of flyers } \\
\text { properly } \\
\text { disposed of }\end{array}$ & $\begin{array}{l}\text { Number } \\
\text { of flyers } \\
\text { discarded to } \\
\text { the ground }\end{array}$ \\
\hline Low & Control & 96 & 59 & 37 & $20(54.05 \%)$ & $17(45.95 \%)$ \\
& Treatment & 110 & 71 & 39 & $15(38.46 \%)$ & $24(61.54 \%)$ \\
High & Control & 81 & 43 & 38 & $29(76.32 \%)$ & $9(23.68 \%)$ \\
& Treatment & 99 & 49 & 50 & $26(52.00 \%)$ & $24(48.00 \%)$ \\
\hline
\end{tabular}

in the parking area itself, all missing flyers were interpreted as being orderly disposed of (i.e. not littered). Since not all students used their bicycles on the days of the observation, the effective number of cases per experimental condition is calculated as the difference between the number of flyers attached in the morning and the number of flyers still attached in the afternoon (Table 1). Variations of case numbers are due to differences in the number of parked bicycles as well as differences in the daily use of bicycles.

The field experiment was first conducted in a clean setting of the parking areas of both dormitories. These observations serve as the control condition. In a repetition 1 week later both parking areas were heavily littered with garbage (Figure 1(b)), using 7 rubbish bags, 14 empty bottles, and 4 cardboard boxes for a disorder condition at each location. ${ }^{2}$ The disorder treatment was explicitly visible upon entering the parking area and could be seen from every location within the parking area. Weather conditions did not vary across treatments and dormitories.

Measurement of local social capital. Extending the original design by Keizer et al. (2008) we chose locations with varying levels of social capital. This allows us to test for the proposed negative social capital effect on norm violations as well as the suggested interaction effect between disorder and the level of local social capital. We started off by assessing the local social capital prevailing in 10 major university dormitories in Munich with a 3 -page paper-and-pencil questionnaire (the survey was conducted 2 weeks before the first experiment took place). The questionnaire was distributed to student inhabitants at the main entrance of each dormitory during weekdays between 17:00 and 20:00. With a participation rate of roughly 50\% the number of returned questionnaires totals 265 ( $n \approx 27$ per dormitory). We collected data on four dimensions of perceived local social capital (Table 2): since Kasarda and Janowitz's (1974) influential paper the relatedness of residents to a place has been a commonly used dimension (e.g. Brown et al., 2004). Furthermore, the frequency (e.g. Bellair, 1997; Brown 
Table 2. Measurement of local social capital in 10 dormitories.

\begin{tabular}{lll}
\hline Dimension (item) Scale $\quad$ Mean SD & $\begin{array}{l}\text { Subindex } \\
\text { consistency } \\
(\alpha)\end{array}$ \\
&
\end{tabular}

\begin{tabular}{|c|c|c|c|c|}
\hline $\begin{array}{l}\text { Relatedness to dorm } \\
\text { If I have personal problems, I } \\
\text { can consult people in my dorm. } \\
\text { I feel related to my dorm. } \\
\text { If I move out, I will stay in } \\
\text { contact to people from my } \\
\text { dorm. }\end{array}$ & ordinal $(0-10)$ & 5.42 & 2.56 & 0.793 \\
\hline $\begin{array}{l}\text { Frequency of shared activities } \\
\text { Common cooking } \\
\text { Common eating } \\
\text { Common sports } \\
\text { Common partying } \\
\text { Common movie lending }\end{array}$ & ordinal $(0-10)$ & 4.06 & 2.33 & 0.812 \\
\hline $\begin{array}{l}\text { Depth of contact } \\
\text { How many people in your } \\
\text { dorm would you call your } \\
\text { friends? } \\
\text { With how many people in your } \\
\text { dorm will you stay in contact } \\
\text { after moving out? }\end{array}$ & metrical $(0-10)$ & 5.40 & 5.13 & 0.806 \\
\hline $\begin{array}{l}\text { Perceived cohesion } \\
\text { Students in the dorm help each } \\
\text { other. } \\
\text { Students know each other well } \\
\text { here. } \\
\text { One can trust students in the } \\
\text { dorm. }\end{array}$ & ordinal $(0-10)$ & 6.38 & 2.15 & 0.753 \\
\hline
\end{tabular}

et al., 2003) and depth of respondents' contact to other inhabitants (e.g. Coleman, 1988, 1990) appears to be an important aspect of community life. Finally, we asked the residents about their perception of the social cohesion in the facilities (e.g. Oberwittler, 2004; Sampson and Raudenbush, 1999). We aggregated the answers to four standardized subindices (each ranging from 0 to 10 ) and subsequently merged them into a single index of self-reported local social capital (z-standardized with mean $=0$ and SD $=1)$. The resulting index is highly consistent $(\alpha=0.798)$, and values of local social capital vary considerably across dormitories (Figure 2). We used this index to distinguish between locations with high and low local social capital. 


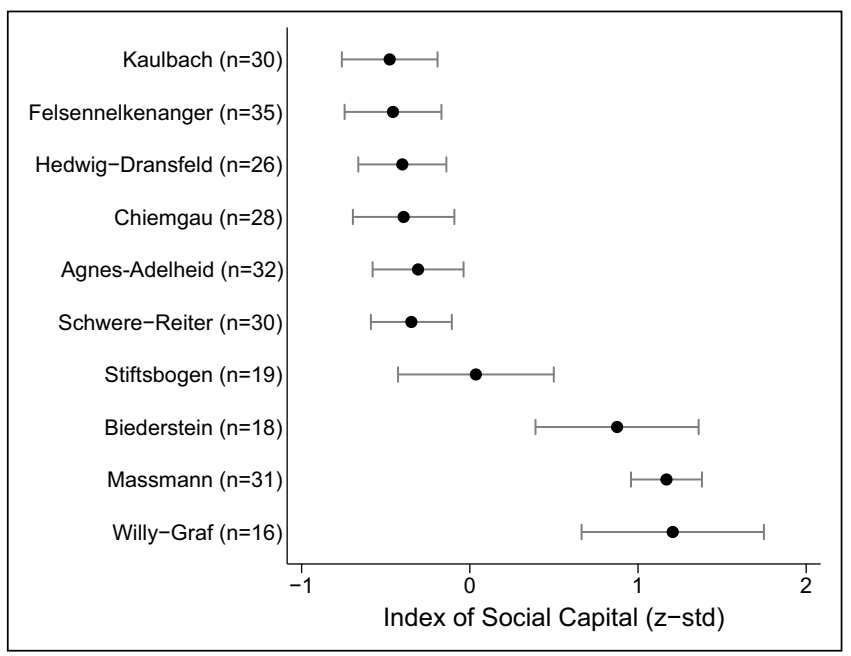

Figure 2. Local social capital across 10 dormitories ( $95 \%$ confidence intervals; number of respondents in parentheses).

Selection of experimental locations. According to our results, there are three types of university dormitories in Munich. Dormitories in the first group (Kaulbach to Schwere-Reiter) lack local social capital. The Stiftsbogen and Biederstein dormitories exhibit a higher degree of local social capital; however, variance of individual answers within these dormitories is too high to distinguish them statistically from either the first or the third type of dormitories. The third group consists of two dormitories (Massmann and Willy-Graf) with a high level of local social capital. Both locations differ significantly from the first group of dormitories $(p<0.05)$. It is worth mentioning that our findings correspond to the application procedure prevalent at the 10 dormitories: while dormitories with low and intermediate levels of local social capital employ a system of centralized application, where the majority of new inhabitants is assigned to a dormitory at random, Massmann and Willy-Graf use a self-organized "casting scheme", where student applicants are hand-picked by the inhabitants themselves. We interpret this congruence of our measurement with the application scheme as an external validation of our local social capital assessment. Thus, we selected Kaulbach as the low and Massmann as the high social capital location of experimentation. ${ }^{3}$ Both dormitories are roughly equal in size (Kaulbach has 97 and Massmann 125 inhabitants) and are situated within the same urban district of Munich, but differ significantly in local social capital $(t=5.238 ; p<0.001)$. Moreover, survey 
participants of both dormitories had been living in their residence for 1.8 years on average, suggesting that dormitories are no transitory places, where inhabitants do not care much about preventing disorder or complying to social rules in general.

\section{Study 2: Jaywalking}

Background. In the second field experiment we investigate a same-norm inhibition effect of social disorder. As opposed to the case of physical disorder, in situations of social disorder norm violators are directly observable by others. Situations of easily observable social disorder frequently occur, for example, at traffic lights where pedestrians cross on red. This form of social disorder is the experimental stimulus as well as the outcome variable of interest. For offenders there is clearly an incentive to save time. However, in Germany and especially in Munich, crossing on red at pedestrian lights is frequently rebuked by bystanders as well as monetarily sanctioned by police. Thus, it classifies as a minor offense against the law and it is not just "city behavior" as it might be interpreted in the US and many other countries. Again, to test for the proposed interaction effect, we conducted the field experiment at pedestrian lights in four urban districts of Munich which differ in local social capital. Each pedestrian light is situated in proximity to a public transportation stop (approximately 500 meters), providing a frequent observation of passers-by.

Experimental set-up. At each of the four street crossings under consideration we defined the street side closest to the public transportation stop as the experimental location. Every passer-by who came alone and crossed the street at the pedestrian light was counted as a subject. Pedestrians, who simultaneously approached the street light and, clearly visible for the focal participant, violated the norm "Stop at a red light", served as the experimental stimulus. Hence, as in study 1 violated norm and target norm are identical. Observations of passers-by facing no or only law-abiding pedestrians serve as the control. Altogether, pedestrians were only counted as subjects if the signal was red and there was no traffic, i.e. crossing the street was principally possible. Moreover, we introduced a stimulus of physical disorder (one garbage bag, one cardboard box, and one empty bottle) next to the pedestrian light. At each location observations were taken for 2 hours on two weekdays in March 2012. Weather conditions were similar across treatment conditions and locations. To describe our sample the number of observations for both experimental conditions at each location is given in Table 3.

Measurement of local social capital. To identify urban districts with substantial differences in social capital we resort to district-level data from the City 
Table 3. Number of cases across city districts and experimental conditions.

\begin{tabular}{lll}
\hline Social capital & Condition & Number of cases \\
\hline Low & Control & 129 \\
& Treatment & 16 \\
High & Control & 29 \\
& Treatment & 13 \\
\hline
\end{tabular}

Table 4. Measurement of local social capital in 20 city districts.

\begin{tabular}{llcc}
\hline Indicator & Description & Mean & SD \\
\hline $\begin{array}{l}\text { Voter } \\
\text { turnout }\end{array}$ & $\begin{array}{l}\text { Percentage of district's registered voters } \\
\text { taking part in 2008 communal election }\end{array}$ & 48.37 & 3.95 \\
$\begin{array}{l}\text { Share } \\
\text { married }\end{array}$ & $\begin{array}{l}\text { Percentage of district's inhabitants being } \\
\text { married in 2009 }\end{array}$ & 38.53 & 4.64 \\
$\begin{array}{l}\text { Share } \\
\text { children }\end{array}$ & $\begin{array}{l}\text { Percentage of district's households with } \\
\text { lichild in 2009 }\end{array}$ & 18.18 & 3.77 \\
$\begin{array}{l}\text { Crime } \\
\text { rate }\end{array}$ & $\begin{array}{l}\text { Number of criminal acts per 100 } \\
\text { inhabitants in 2009 }\end{array}$ & 5.02 & 1.42 \\
\hline
\end{tabular}

of Munich (Munich Statistics Agency, 2010). We restrained from measuring social control on the individual level as in study 1 , since on the district level the units of social capital formation are considerably larger and poorly confined. As local social capital is not easily observable, we constructed an index from related variables. Albeit these indicators hardly measure local social capital itself, as they are either preconditions or consequences of the concept to be measured, we believe that using corollaries of local social capital captures the concept quite well. Following the literature on local social capital (e.g. van Deth, 2003) the index consists of four district specific variables (see Table 4). First, political participation has been identified as a central corollary of local involvement (e.g. Perkins and Long, 2002; Putnam, 2000). Hence, we use the voter turnout in the latest communal election (2008) as an indicator for the level of neighborhood engagement. Second, the period of residence has been found to affect feelings of commitment and responsibility towards a neighborhood (e.g. Brown et al., 2003; Hipp and Perrin, 2006). We include two indicators which positively correlate with housing duration, i.e. the share of married inhabitants and the share of households with children. Both, being married and raising children are positively linked to increased neighborhood ties (e.g. Franzen and Pointner, 2007) and community participation (e.g. Putnam, 2000). Third, we include 


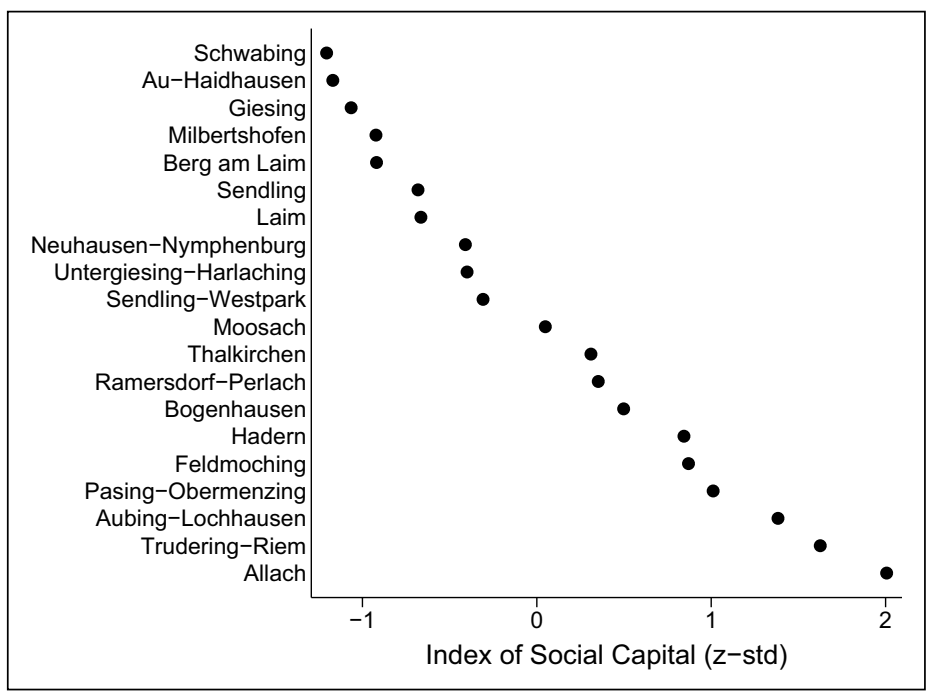

Figure 3. Local social capital across 20 city districts in Munich.

the inverse of the district specific crime rate, as it is a direct consequence of local social control (data from 2009). To ensure that participants in our field experiment live around the area of observation, we excluded all predominantly commercial districts from our analysis, leaving us with 20 mainly residential districts. With $\alpha=0.761$ the index is highly consistent, and values vary substantially (Figure 3).

Selection of experimental locations. To test our hypotheses with regard to local social capital we selected four neighborhoods which substantially differ in this variable and offer a pedestrian street light which is suitable for our experimental set-up. After a visual examination of appropriate sites in neighborhoods with either high or low local social capital, we chose the districts of Allach and Trudering-Riem (high social capital) as well as Schwabing and Giesing (low social capital) for our field experiment. The selected districts strongly differ in local social capital, but are comparable in socioeconomic composition (e.g. age, gender, poverty rate, and unemployment; for data see Munich Statistics Agency, 2010). Being aware of the deficits of our social capital measurement we cross-validated our index with data on "social challenges" in the 20 districts under consideration (see Munich Sozialreferat, 2012). The official indicator consists of district-level variables measuring the number of interventions for child protection, the share of households supported by social workers, receiving 


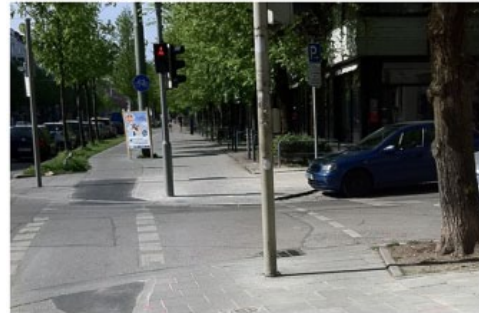

(a)

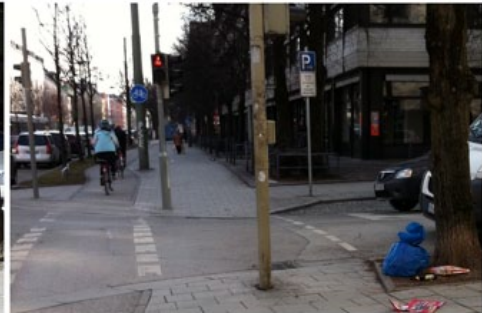

(b)

Figure 4. Pedestrian light in the condition of order and physical disorder.

child welfare, or depending on social welfare programs as well as the share of migrant inhabitants. Both measures yield similar results: while Schwabing and Giesing score high in "social challenges", Allach and Trudering-Riem feature very low values consistent with our measurement of local social capital.

To limit the influence of unobservables, the pedestrian lights had to provide a comparable situational context. The street lights we chose are particularly set up for pedestrians, each situated on a road of roughly equal size and with minor car traffic. There are no shops, restaurants, or bars near any of the four locations, and buildings or trees helped to conceal the experimenter (see Figure 4 for an example site).

\section{Study 3: Helping and stealing}

Background. In the third field experiment we test for cross-norm inhibition effects. Following Keizer et al. (2008), we used the lost letter technique (Merritt and Fowler, 1948; Milgram et al., 1965; Simmons and Zumpf, 1983) as well as a systematic variation of the degree of physical disorder to induce spillovers of norm violations. The outcome variables of interest are helping and stealing behavior. To incentivize norm violations the envelope displayed money $(5,10$, or 100 Euros) through the address window. The experiment was conducted at public mail boxes situated in two urban districts of Munich with either high or low local social capital. Again, this variation allows to test for the suggested social capital effects.

Experimental set-up. In order to observe helping or stealing behavior of our participants we placed a "lost" letter in front of the mail box in each district. In contrast to Keizer et al. (2008), our "lost" letter was placed in front of the mail box (not sticking out of it), enabling us to observe three possible reactions by each passer-by: no action, stealing, or helping. While no reaction is 


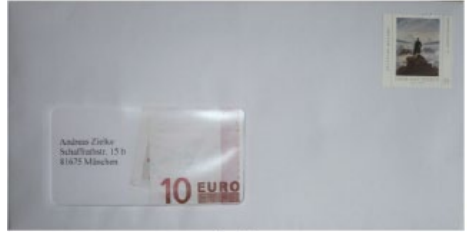

(a)

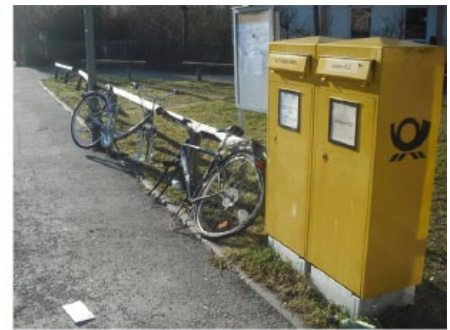

(b)

Figure 5. "Lost" letter with incentive to steal; disorder condition at a mail box.

Table 5. Number of cases per mail box and experimental conditions.

\begin{tabular}{lccc}
\hline \multirow{2}{*}{$\begin{array}{l}\text { Amount } \\
\text { displayed }\end{array}$} & \multicolumn{2}{c}{ Condition } & Total \\
\cline { 2 - 3 } & Control & Treatment & \\
\hline 5 Euros & 45 & 45 & 90 \\
10 Euros & 45 & 45 & 90 \\
100 Euros & 45 & 45 & 90 \\
Total & 135 & 135 & 270 \\
\hline
\end{tabular}

a violation of the weak prosocial norm "Put lost letters in the mail box" we interpret stealing as a violation of the strong legal norm "Don't steal lost letters". Each letter was prepared with a visible incentive to steal (Figure 5(a)). In extension to Keizer et al. (2008), the amount displayed through the address window of the envelope varied between 5, 10, and 100 Euros. Taking into account that running off with a 5 or 10 Euro note is (legally as well as socially) less severely punished than stealing 100 Euros, the variation of notes gives some indication whether the explanatory power of the BWT decreases with the strength of norm violations (incentivization effect).

Each passer-by who noticed the clearly visible letter was counted as a subject. If the participant put the envelope in the mail box or stole it, the lost letter was replaced by a new one, once the passer-by had left the location. In both urban districts the procedure was repeated until there were 270 observations completed at each location (135 in the control and 135 in the treatment condition). After 45 observations the amount of money on display was changed. The number of cases per location is given in Table 5 .

In the control condition the areas surrounding both mail boxes were kept clean. In the treatment condition we attached two heavily wrecked bicycles to a railing next to the mail boxes (Figure 5(b)). This stimulus of physical disorder was clearly visible for every passer-by. Data collection took 3-4 
days per location and experimental condition (approximately 4 hours a day). The whole experiment was conducted on weekdays only, starting from early November to late December 2011. Control and treatment conditions were alternated twice, starting with a clean surrounding at both locations. Since we wanted to avoid the envelopes getting wet, the experiment was only staged on clear days. Thus, weather conditions did not substantially change throughout the experiment.

Selection of experimental locations. Based on the district-level assessment described in study 2 we staged the experiment at the two districts which rank highest (Allach) and lowest (Schwabing) in local social capital (Figure 3). Allach is a suburban residential area on the north-western outskirts of Munich with 29,000 inhabitants. Schwabing is a residential district located in central Munich with 128,000 inhabitants. Except for social capital, both districts are comparable in their sociodemographic composition. In each district we selected a suitable public mail box for experimentation. Both mail boxes had to be similar in location, visibility, and frequency of usage. Thus, we selected mail boxes located at broad and regularly frequented streets, both in proximity to public transportation stops (approximately 150 meters). Again, at both locations there were no shops, restaurants, or bars nearby. Both locations facilitated concealed observation from a parked car.

\section{Results}

The results section is structured in three parts. First, we present our evidence for the same-norm inhibition effect with respect to physical disorder (i.e. visual cues for previous norm violations; study 1) and social disorder (i.e. directly observed norm violations by others; study 2). Second, we describe our findings concerning the spillover of norm violations (study 3 ), where we distinguish between socially and legally enforced target norms and vary the incentive for deviance. Third, we summarize suggestive evidence on the effect of local social capital on the rate of norm violations as well as on the varying strength of disorder signals as a function of the degree of local social capital prevailing at the experimental location. To identify statistically significant differences between experimental conditions we report two-sided $\chi^{2}$ tests.

\section{Same-norm inhibition effect}

Study I: Littering. Results from the littering experiment clearly show a samenorm inhibition effect (Figure 6(a)). The frequency of norm violation is significantly higher when participants are confronted with the same norm 


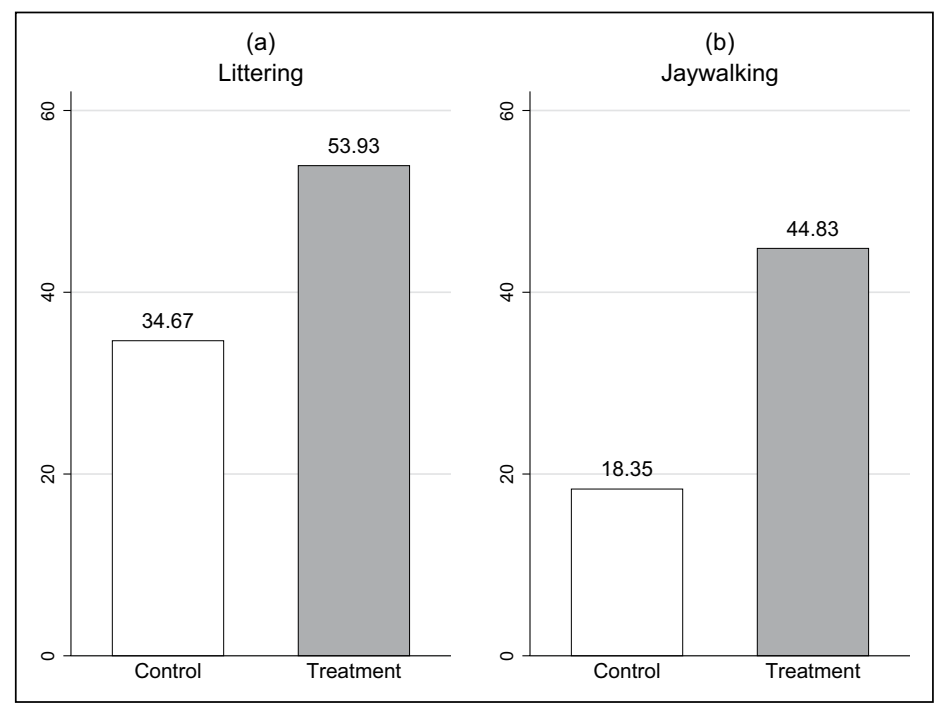

Figure 6. Same-norm inhibition effect.

already broken $\left(\chi^{2}(1,164)=6.101, p=0.014\right)$. Moreover, the observed rates of norm violation across both dormitories, $34.7 \%$ in the control and $53.9 \%$ in the treatment condition, correspond in direction and size to earlier findings from The Netherlands (Keizer et al., 2008).

Study 2: Jaywalking. In addition to this replication of earlier findings our experiment on jaywalking confirms the same-norm inhibition effect with respect to social disorder (Figure 6(b)). Across all four experimental locations participants facing pedestrians crossing against the light show a higher rate of deviance $(44.8 \%)$ than subjects from the control group (18.4\%). The difference in the rate of deviant behavior is highly significant $\left(\chi^{2}(1,187)=\right.$ $9.860, p=0.002)$. When introducing an additional stimulus of physical disorder we find no significant treatment effect. In a littered environment, however, the effect of social disorder is stronger $\left(\chi^{2}(1,82)=7.025\right.$, $p=0.008)$ than in a clean setting $\left(\chi^{2}(1,105)=3.663, p=0.056\right)$. Interestingly, physical disorder reinforces the effect of social disorder.

\section{Cross-norm inhibition effect}

Study 3: Helping. Looking at the socially sanctioned target norm first, we find less helping behavior in the condition of physical disorder (11.9\%) as compared with the control treatment (19.3\%; see Figure 7(a)). Across both 


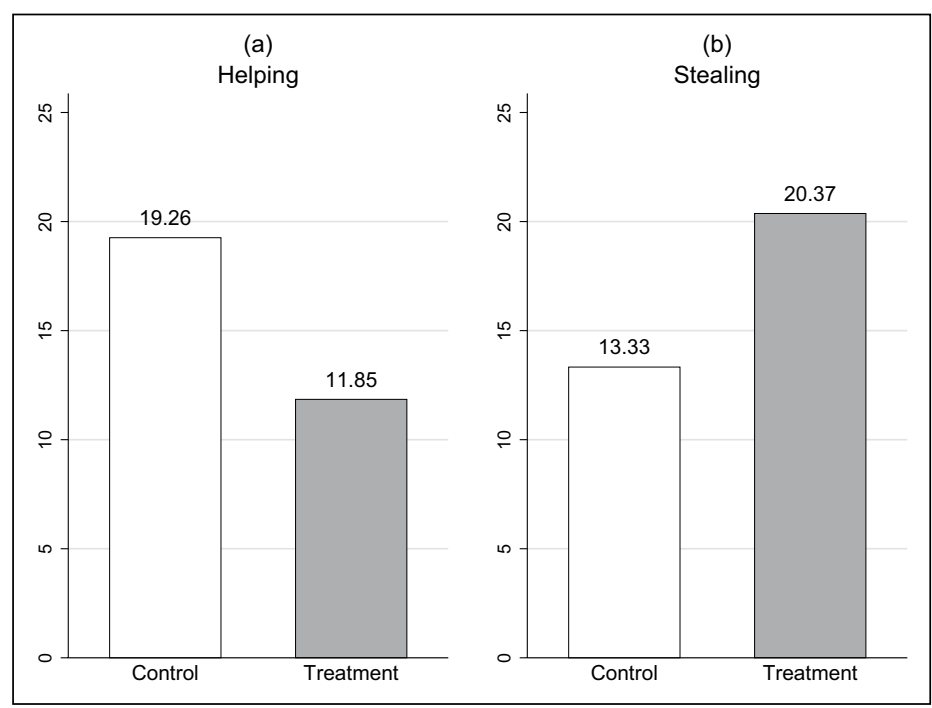

Figure 7. Cross-norm inhibition effect.

experimental locations this difference is significant $\left(\chi^{2}(1,540)=5.639\right.$, $p=0.018)$. Clearly, this finding is consistent with mechanism 1 which implies a spillover effect of norm violations. Apparently, when exposed to physical disorder participants perceive the violation of minor norms as legitimate.

Study 3: Stealing. Also in the case of a legally sanctioned target norm there is evidence for the cross-norm inhibition effect. While in the clean condition $13.3 \%$ of our subjects steal the "lost" letter, the thieving rate increases to $20.4 \%$ in the face of physical disorder (Figure 7(b)). Again, the difference is significant $\left(\chi^{2}(1,540)=4.771, p=0.029\right)$. This finding closely corresponds to prior results from Keizer et al. (2008).

In addition, our variation of incentives to steal offers insights on the applicability of the BWT to situations of more severe sanctions. As mentioned above, we expect individuals to react to contextual cues more strongly in situations where norm violations are only moderately sanctioned. Hence, physical disorder should have a stronger effect on the rate of stealing when there is only a minor amount of money displayed through the address window of the envelope. Our results corroborate this consideration: envelopes containing a 5 Euro note are stolen far more often in the face of disorder (21.1\%) than under a clean condition $(10.0 \%)\left(\chi^{2}(1,180)=4.229, p=0.040\right)$. If 10 Euro notes are on display, we find a slightly weaker treatment effect $\left(\chi^{2}(1,180)=2.756\right.$, 


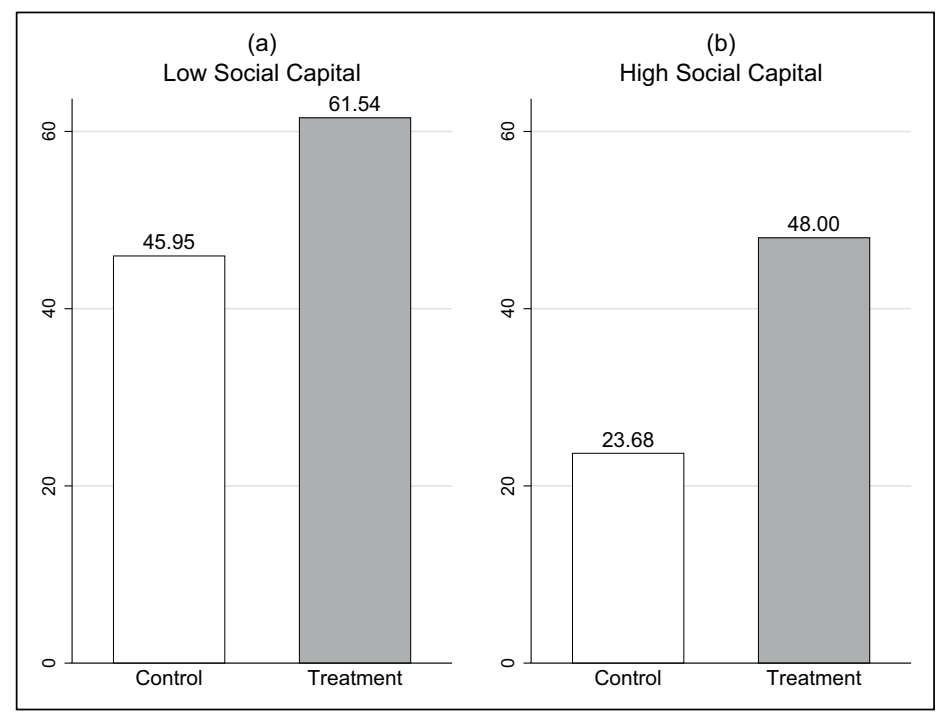

Figure 8. Disorder, social capital, and littering.

$p=0.097)$. In cases of 100 Euro notes, the disorder effect disappears completely $\left(\chi^{2}(1,180)=0.000, p=1.000\right)$. This finding is well in line with the incentivization hypothesis, according to which the relative importance of environmental cues diminishes with increasing costs and benefits.

\section{Consequences of local social capital}

Study I: Littering. To check for an interaction of physical disorder and social capital we test for a same-norm inhibition effect separately at each dormitory (Figure 8). First, we find evidence for the main effect of local social capital. The basic rate of norm violation is higher if social capital is low $\left(\chi^{2}(1,75)=\right.$ $4.102, p=0.043)$. Second, a large and significant treatment effect occurs only at the high social capital location $\left(\chi^{2}(1,88)=5.447, p=0.020\right)$, while disorder has no significant effect at the low social capital location $\left(\chi^{2}(1,76)\right.$ $=1.858, p=0.173)$. Altogether, the differences-in-differences estimator shows that the disorder effect is 8.8 percentage points larger in the high social capital than in the low social capital scenario. This finding is in line with the proposed interaction effect of physical disorder and social capital.

Study 2: Jaywalking. A separate analysis for districts with high or low social capital provides no evidence for the main effect of social capital (Figure 9). As in the control condition the baseline rate of compliance is almost equal 


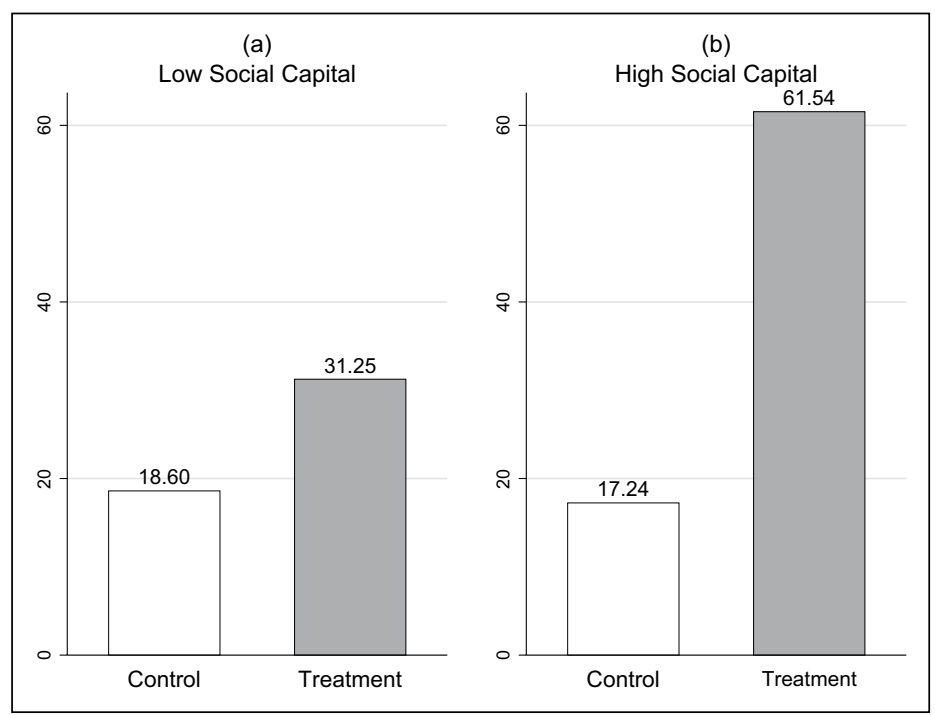

Figure 9. Disorder, social capital, and jaywalking.

across locations with high or low local social capital. However we find the expected interaction effect of social disorder and local social capital. While social disorder shows no significant effect in the low social capital scenario $\left(\chi^{2}(1,145)=1.423, p=0.223\right)$, there is a strong treatment effect in the districts with high social capital $\left(\chi^{2}(1,42)=8.241, p=0.004\right)$. As a consequence, the deteriorating effect of social disorder is 31.7 percentage points larger in "good" than in "bad" neighborhoods.

Study 3: Helping. Looking first at minor norm violations (i.e. the absence of helping behavior) our results reveal small but insignificant differences between locations with high $(21.5 \%)$ and low social capital (17.0\%). Nonetheless, we find a significant treatment effect at the high social capital location $\left(\chi^{2}(1,270)=6.224, p=0.013\right)$, with less than half as many helpers in the disorder as in the control condition (Figure 10). However, the rate of norm violation does not significantly change in the low social capital scenario $\left(\chi^{2}(1,270)=0.719, p=0.396\right)$. As a result, the spillover effect of norm violation is 7.4 percentage points larger in the city district with high local social capital. Just as in studies 1 and 2, this finding suggests a positive interaction of disorder and local social capital.

Study 3: Stealing. The basic level of stealing in the control condition is slightly lower if social capital is high ( $11.9 \%$ as compared with $14.8 \%$ when local 


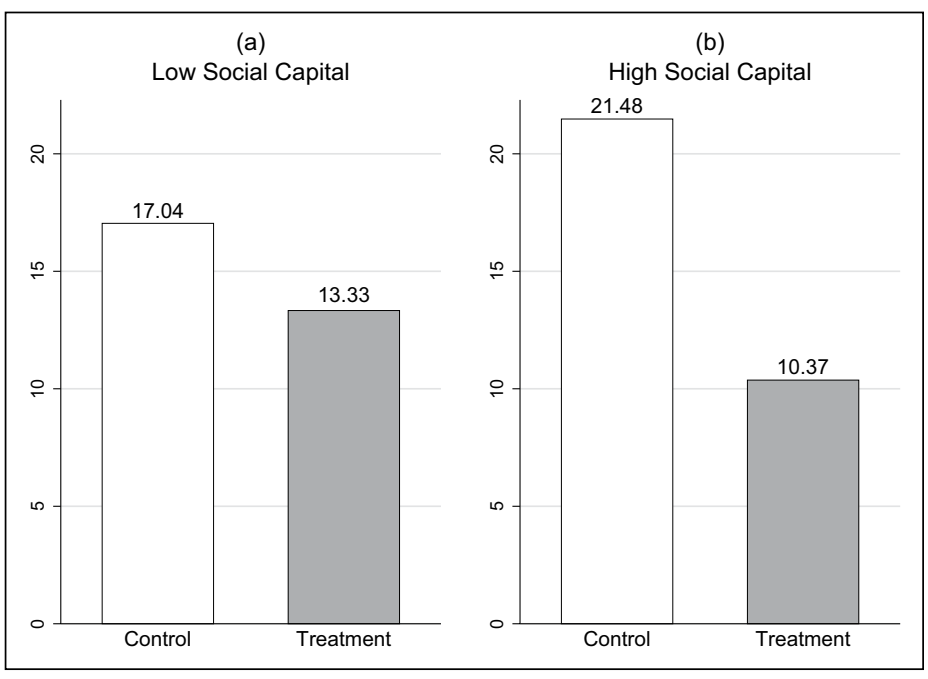

Figure 10. Disorder, social capital, and helping.

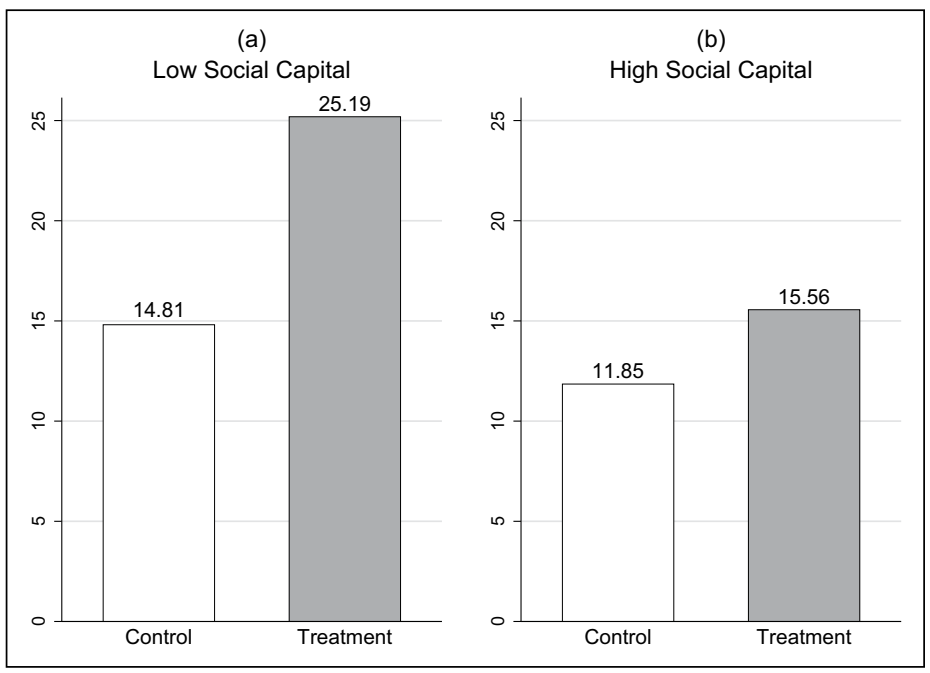

Figure I I. Disorder, social capital, and stealing.

social capital is low; Figure 11). Disorder promotes stealing only at the low social capital location $\left(\chi^{2}(1,270)=4.537, p=0.033\right)$, whereas we find no significant treatment effect at the high social capital location $\left(\chi^{2}(1,270)=\right.$ 
$0.783, p=0.376$ ). This finding clearly differs from our previous results on the interaction effect of disorder and social capital in low-cost situations. The seeming contradiction can be resolved by taking into account that costs and benefits are higher in the context of stealing. Once stakes are high, the relevance of environmental cues diminishes. A baseline expectation of sanctioning derived from the knowledge about local social capital dominates signals of disorder. Consequently, in high-cost situations behavior is only affected if both signals of low social control coincide. Unlike in cases of weak norms signals of order-maintenance are no substitute for a neighborhood's social capital in high-cost situations.

\section{Discussion}

We add to the debate about the BWT by presenting a rational choice explanation of norm-violating behavior, where the possibility of punishment is inferred from contextual cues in low-cost, but not in high-cost situations. Assuming that disorder signals reactions to previous norm violations we expected individuals to lower their beliefs on the probability and severity of social sanctions in situations with physical or social disorder. Since in high-cost situations it pays to invest in costly search to gain objective information on rates of punishment and to actively ponder the costs and benefits of deviance, our approach particularly applies to situations of minor norm violations. Varying the incentives for deviance we were able to investigate the scope conditions of the BWT. Furthermore, we extended the "broken windows" framework by the rather neglected influence of local social capital and its interaction with disorder. Thereby, the strength of the disorder signal and, thus, the effects of disorder should be stronger in high social capital contexts.

Following the interventionist approach of Keizer et al. (2008) we implemented three field experiments on littering, jaywalking, and helping/ stealing to test our theoretical considerations. Stimuli of physical disorder induced further littering, less helping, and more stealing of lost letters. Moreover, we were able to show a same-norm inhibition effect not only for physical, but also for social disorder. One conclusion from these findings is that early preventions of minor norm violations influence people's beliefs about the probability and severity of social sanctions and will avert further violations of the same norm as well as of different norms of minor severity.

Also consistent with our theoretical framework we found suggestive evidence on the consequences of local social capital of a neighborhood, which significantly moderates disorder effects. As theoretically expected, in the baseline condition of our experiments norm violations occurred less often in areas highly endowed with social capital. Moreover, in low cost situations 
the reaction to the disorder treatment was significantly stronger in these districts. As expected, the strength of the signal varied with the social context. Public actions to remove disarray seem to be especially effective in "good" neighborhoods. However, this does not hold true for stealing for which we found a stronger treatment effect in the low social capital area. It appears that when target norms are rigorous, disorder seems to affect behavior only if social control is generally low. Unlike in cases of weak norms, such as anti-littering or helping conventions, order maintenance is no substitute for a neighborhood's collective efficacy.

In line with the incentivization hypothesis we found no disorder effect for stealing 100 Euro notes. This suggests that individuals care less about environmental cues in high-cost situations and, instead, ponder the actual net benefits from deviance. As costs and benefits of deviance increase, contextual cues become less important for individual decision making. Hence, we expect that disorder treatments have even weaker effects on more serious forms of crime than on deviant behavior, such as littering, jaywalking, abstaining from helping, and petty stealing. Consequently, fixing broken windows inhibits minor norm violations but might not avert serious crime: small-scale disorder breeds small-scale norm violation, but not necessarily crime at a high level. Still, since stealing a lost letter was the most severe crime we could induce in the experimental setting, we cannot definitely answer the question whether environmental cues are only relevant in cases of minor norm offenses.

Although our field experiments identify responses to quasi-random stimuli of different norm violations and appear to offer valuable insights on the effects of disorder on social norms, some drawbacks remain. First, the lack of more adequate measures of local social capital inhibited a better test of the extension of the theoretical framework by district-level social capital and its interaction with order maintenance. As suggested by Perkins and Long (2002) and van Deth (2003) we used voter turnout in the latest elections, the proportion of married inhabitants, the proportion of households with children, and the inverse crime rate as indicators for local social capital. These indicators are surely only imperfect measures for the theoretical constructs of interest, but, as our external validations suggest, they offer at least raw approximations.

Second, we could only provide suggestive evidence on the consequences of local social capital, since subjects were not randomly assigned to the different locations. Apart from our experimental conditions it is possible that locations with high or low social capital and the respective subjects of our study systematically differ in variables relevant for the outcome. We have, in fact, tested for local differences with regard to a series of variables which appeared to be important determinants of norm 
violation and can rule out this possibility. As well, the fact that we found similar effects in three independent experimental studies at different locations increases our confidence in the validity of these results. However, we cannot finally rule out the possibility that unobservables on the individual and local level bias the estimates of local social capital effects and its interaction with disorder.

Third, questions on the relative importance of disorder signals and local social capital remain open to future research. On the one hand, our results indicate an interaction of both concepts. As a consequence, policies which try to outweigh disorder effects by increasing social capital might not be a panacea. Concerning minor norm violations, an increase in social capital strengthens disorder effects. On the other hand, higher levels of local social capital are associated with lower base rates of deviance. Since both concepts were treated as binary variables in this study, we cannot definitely answer the question how both effects combine. A precondition to determine the exact trade-off between the direct and indirect effect of social capital is to comparably measure both concepts. Such a measure would be a worthwhile contribution, yet, it is beyond the scope of this paper.

Finally, our field experiments do not allow us to study the cumulative spreading of disorder over longer periods of time. Such processes are frequently observed in the context of residential segregation, ethnic conflict and neighborhood decline, and play a crucial part in the theoretical discussion about "broken windows" effects. Thus, although our findings raise doubts about the importance of order-maintenance for the prevention of serious crime, our field experiments should not be understood as a final answer on the validity of the BWT.

\section{Acknowledgements}

We thank Simon Foresta (study 1), Martina Hainzlmaier (study 2), Andreas Bauer, and Florian Haider (both study 3) for data collection and Norman Braun, Jose Antonio Hernandez Company, Martina Kroher, Patrick Riordan, Margret Szymanski-Schikora, and two anonymous reviewers for helpful comments. This paper received the Anatol Rapoport Award 2014 from the section "Model Building and Simulation" of the German Sociological Association. M.K. and T.W. contributed equally to this work.

\section{Funding}

This research received funding from the Ludwig-Maximilians-University Munich.

\section{Notes}

1. Of course it would be interesting to study more serious crime. However, in our field experimental approach it is impossible to test the applicability of the 
proposed theoretical mechanisms to severe crime, such as robbery, rape or murder.

2. The non-random ordering of treatment and control conditions opens the possibility that people may be willing to incur the cost of norm compliance once, but not twice. Students may become frustrated by finding the flyer again and simply throw it on the ground. Still, we deliberately chose this design in order to directly replicate the study by Keizer et al. (2008). For future research we recommend a random timing of treatment and control conditions.

3. Owing to the low number of respondents to our survey $(n=16)$ and therefore its unreliable social capital score Willy-Graf dormitory was excluded from the field experiment.

\section{References}

Becker GS (1968) Crime and punishment: An economic approach. Journal of Political Economy 76: 169-217.

Bellair PE (1997) Social interaction and community crime: Examining the importance of neighbor networks. Criminology 35: 677-703.

Bicchieri C (2006) The Grammar of Society: The Nature and Dynamics of Social Norms. New York: Cambridge University Press.

Bicchieri C and Xiao E (2009) Do the right thing: But only if others do so. Journal of Behavioral Decision Making 22: 191-208.

Bourdieu P (1984) Distinction: A Social Critique of the Judgment of Taste. Cambridge: Harvard University Press.

Braga AA and Bond BJ (2008) Policing crime and disorder hotspots: A randomized controlled trial. Criminology 46: 577-607.

Braun N and Gautschi T (2011) Rational Choice Theorie. Weinheim and München: Juventa.

Brown BB, Perkins DD and Brown G (2003) Place attachment in a revitalizing neighborhood: Individual and block levels of analysis. Journal of Environmental Psychology 23: 259-271.

Brown BB, Perkins DD and Brown G (2004) Incivilities, place attachment and crime: Block and individual effects. Journal of Environmental Psychology 24: 359-371.

Brown WW and Reynolds MO (1973) Crime and punishment: Risk implications. Journal of Economic Theory 6: 508-514.

Browning CR, Feinberg SL and Dietz RD (2004) The paradox of social organization: Networks, collective efficacy, and violent crime in urban neighborhoods. Social Forces 83: 503-534.

Burt RS (1992) Structural Holes: The Social Structure of Competition. Cambridge: Harvard University Press.

Cialdini RB (2007) Descriptive social norms as underappreciated sources of social control. Psychometrika 72: 263-268.

Cialdini RB, Reno RR and Kallgren CA (1990) A focus theory of normative conduct: Recycling the concept of norms to reduce littering in public places. Journal of Personality and Social Psychology 58: 1015-1026. 
Coleman JS (1988) Social capital in the creation of human capital. American Journal of Sociology 94: S95-S120.

Coleman JS (1990) Foundations of Social Theory. Cambridge: Belknap Press of Harvard University Press.

Corman H and Mocan N (2005) Carrots, sticks, and broken windows. Journal of Law and Economics 48: 235-266.

Diekmann A, Przepiorka W and Rauhut H (2011) Lifting the veil of ignorance: An experiment on the contagiousness of norm violations. CESS Discussion Paper 2011004, University of Oxford, Nuffield College.

Franzen A and Pointner S (2007) Sozialkapital: Konzeptualisierungen und Messungen. In: Franzen A and Freitag M (eds), Sozialkapital: Grundlagen und Anwendungen. Wiesbaden: VS Verlag, pp. 66-90.

Franzen A and Pointner S (2012) Anonymity in the dictator game revisited. Journal of Economic Behavior and Organisation 81: 74-81.

Fukuyama F (1995) Trust: The Social Virtues and the Creation of Prosperity. New York: Free Press.

Granovetter M (1973) The strength of weak ties. American Journal of Sociology 78: 1360-1380.

Harcourt BE and Ludwig J (2006) Broken windows: New evidence from New York City and a five-city social experiment. University of Chicago Law Review 73: 271-320.

Heineke JM (1975) A note on the criminal choice problem. Journal of Economic Theory 10: 113-116.

Hipp JR and Perrin A (2006) Nested loyalties: Local networks' effects on neighbourhood and community cohesion. Urban Studies 43: 2503-2523.

Kasarda J and Janowitz M (1974) Community attachment in mass society. American Sociological Review 39: 328-339.

Keizer K, Lindenberg S and Steg L (2008) The spreading of disorder. Science 322: 1681-1685.

Keizer K, Lindenberg S and Steg L (2011) The reversal effect of prohibition signs. Group Processes and Intergroup Relations 14: 681-688.

Kelling GL and Coles C (1996) Fixing Broken Windows: Restoring Order and Reducing Crime in Our Communities. New York: Free Press.

Kelling GL and Sousa WH Jr (2001) Do Police Matter? An Analysis of the Impact of New York City's Police Reforms. New York: Center for Civic Innovation at the Manhattan Institute.

Kirchgässner G (1992) Towards a theory of low-cost decisions. European Journal of Political Economy 8: 305-320.

Kliemt H (1986) The veil of insignificance. European Journal of Political Economy 2: 333-344.

Levitt SD (2004) Understanding why crime fell in the 1990s: Four factors that explain the decline and six that do not. Journal of Economic Perspectives 18: 163-190.

Markowitz FE, Bellair PE, Liska AE and Liu J (2001) Extending social disorganization theory: Modeling the relationships between cohesion, disorder, and fear. Criminology 39: 293-320. 
Merritt CB and Fowler RB (1948) The pecuniary honesty of the public at large. Journal of Abnormal and Social Psychology 43: 90-93.

Milgram S, Mann L and Harter S (1965) The lost letter-technique: A tool of social research. Public Opinion Quarterly 29: 437-438.

Munich Sozialreferat (2012) Monitoring für das Sozialreferat 2011. Munich, Germany.

Munich Statistics Agency (2010) Statistisches Jahrbuch 2010. Munich, Germany.

Oberwittler D (2004) A multilevel analysis of neighbourhood contextual effects on serious juvenile offending: The role of subcultural values and social disorganization. European Journal of Criminology 1: 201-235.

Opp KD (1983) Die Entstehung sozialer Normen: Ein Integrationsversuch soziologischer, sozialpsychologischer und ökonomischer Erklärungen. Tübingen: Mohr Siebeck.

Opp KD (2002) When do norms emerge by human design and when by the unintended consequences of human action? The example of the no-smoking norm. Rationality and Society 14: 131-158.

Ostrom E (1999) Social capital: A fad or a fundamental concept? In: Dasgupta P and Serageldin I (eds) Social Capital: A Multifaceted Perspective. Washington, DC: The World Bank, pp. 172-214.

Ostrom E and Ahn TK (eds) (2003) Foundations of Social Capital. Cheltenham: Edward Elgar.

Perkins D and Long A (2002) Neighborhood sense of community and social capital: A multi-level analysis. In: Fisher A, Sonn CC and Bishop BJ (eds), Psychological Sense of Community: Research, Applications, and Implications. New York: Kluwer, pp. 291-317.

Popitz H (1968) Über die Präventivwirkung des Nichtwissens: Dunkelziffer, Norm und Strafe. Tübingen: Mohr.

Putnam RD (2000) Bowling Alone: The Collapse and Revival of American Community. New York: Simon \& Schuster.

Rosenbaum PR (2010) Design of Observational Studies. New York: Springer.

Rubin DB (2008) For objective causal inference, design trumps analysis. Annals of Applied Statistics 2: 808-840.

Sampson RJ, Raudenbush SW and Earls F (1997) Neighborhoods and violent crime: A multilevel study of collective efficacy. Science 277: 918-924.

Sampson RJ and Raudenbush SW (1999) Systematic social observation of public spaces: A new look at disorder in urban neighborhoods. American Journal of Sociology 105: 603-651.

Sampson RJ, Morenoff JD and Gannon-Rowley T (2002) Assessing 'neighborhood effects': Social processes and new directions in research. Annual Review of Sociology 28: 443-478.

Silver E and Miller LL (2004) Sources of informal social control in Chicago neighborhoods. Criminology 42: 551-583.

Simmons CH and Zumpf C (1983) The lost letter technique revisited. Journal of Applied Social Psychology 13: 510-514. 
Skogan WG (1990) Disorder and Decline: Crime and the Spiral of Decay in American Neighborhoods. Berkeley: University of California Press.

Steenbeek W and Hipp JR (2011) A longitudinal test of social disorganization theory: Feedback effects among cohesion, social control, and disorder. Criminology 49: 833-871.

Van Deth JW (2003) Measuring social capital: Orthodoxies and continuing controversies. International Journal of Social Research Methodology 6: 79-92.

Wilson JQ and Kelling GL (1982) Broken windows: The police and neighborhood safety. The Atlantic Monthly (March): 29-39. 